FARIA RT; TAKAHASHI LSA; LONE AB; BARBOSA CM; TAKAHASHI A; SILVA GL. 2011. UEL 7: nova cultivar de Dendrobium. Horticultura Brasileira 29: 441-442.

\title{
UEL 7: nova cultivar de Dendrobium
}

\author{
Ricardo Tadeu de Faria; Lúcia SA Takahashi; Alessandro B Lone; Cristiane M Barbosa; Alexandre \\ Takahashi; Geraldo L da Silva \\ UEL-Depto. Agronomia, C. Postal 6001, 86051-990 Londrina-PR; faria@uel.br
}

\begin{abstract}
RESUMO
UEL 7 é uma cultivar de Dendrobium nobile desenvolvida no Departamento de Agronomia da Universidade Estadual de Londrina resultante do cruzamento das plantas matrizes D3 x D8 e selecionada pela coloração das flores amarelas e com largura e comprimento semelhantes $(7,0 \mathrm{~cm})$, formando praticamente um círculo. As plantas foram polinizadas artificialmente, e as sementes semeadas em meio de cultura in vitro. A cultivar apresenta flores de coloração amarela, labelo com o centro marrom escuro e o pseudobulbo apresenta em média 11 flores. As flores têm durabilidade de aproximadamente 30 dias.
\end{abstract}

Palavras chave: Dendrobim nobile, descrição de cultivar, melhoramento, orquídea.

\begin{abstract}
UEL 7: a new Dendrobium cultivar

UEL 7 is a Dendrobium nobile's cultivar developed at The Department of Agronomy of Universidade Estadual de Londrina and is the result of the crossing between D3 x D8 and selected for its yellow flowers and format with similar width and length $(7.0 \mathrm{~cm})$, almost forming a circle. The plants were pollinated artificially, and the seeds sowed in growth media in vitro. The cultivar presents flowers of yellow coloration, labelo with the center dark brown color and the pseudobulb presents 11 flowers on average. The flowers durability is about 30 days.
\end{abstract}

Keywords: Dendrobim nobile, breeding, cultivar description, orchid.

(Recebido para publicação em 20 de dezembro de 2010; aceito em 18 de agosto de 2011)

(Received on December 20, 2010; accepted on August 18, 2011)

$\mathrm{O}$ setor de floricultura ocupa uma área estimada em 190 mil ha e movimenta mundialmente US\$ 18 bilhões (base mercado produtor) e US\$ 54 bilhões (base mercado consumidor). No Brasil, os números no varejo giram em torno de R\$2,6 bilhões. O mercado produtor movimenta R\$ 700 milhões e o atacadista R\$ 1,1 bilhão (ABCSEM, 2011).

A média anual de consumo de flores e plantas ornamentais no Brasil é de $\mathrm{R} \$ 13,00$ a $\mathrm{R} \$ 15,00$ por pessoa, muito abaixo do consumo per capita europeu, que é de US\$ 70,00 por habitante/ano. O Brasil possui cerca de 5,1 mil produtores de plantas e flores de todos os tamanhos responsáveis pelo cultivo de quase oito mil hectares (ABCSEM, 2011).

Em relação às exportações de orquídeas, o valor total foi de US\$ 219,86 mil em 2009. Os principais países de destino foram Japão (53,08\%), Alemanha $(21,74 \%)$, EUA $(12,27 \%)$ e Holanda
(8,08\%), além de Ucrânia, Taiwan, Hong Kong, África do Sul e Chile (Junqueira \& Peetz, 2011).

Dendrobium nobile Lindl. é uma espécie de folhas renováveis, caules eretos, atingindo $30-40 \mathrm{~cm}$ de altura, com grupos de duas a três flores (de cerca de 7,0 cm de diâmetro) por nó e é muito utilizada na obtenção de híbridos comerciais (Suttleworth et al, 1913, tradução Lema Filho, 1994).

Para plantas em vaso, como é o caso de grande parte das orquídeas, as características desejáveis são flores atraentes, duradouras, principalmente em condições de escritórios, mínimo de dois pseudobulbos por planta florescendo e com grande número de flores, pseudobulbos menores $( \pm 60 \mathrm{~cm})$ e múltiplos e folhas verdes (Kamemoto et al., 1999).

O objetivo do trabalho foi a obtenção de cultivar de $D$. nobile a partir de cruzamentos realizados entre matrizes selecionadas.

\section{MÉTODO DE MELHORAMENTO}

No Departamento de Agronomia, em 1997, iniciaram-se os trabalhos de melhoramento de Dendrobium nobile a partir de cruzamentos de matrizes selecionadas e obtida uma cultivar, a UEL 6 (Faria et al, 2009). UEL 7 é uma cultivar obtida neste programa de melhoramento.

UEL 7 é originada do cruzamento das plantas matrizes D3 x D8 selecionadas pela coloração branco-amarelada, maior número e tamanho de flores, porte da planta e época de florescimento. As plantas foram polinizadas artificialmente, e, após nove meses, obtidas as cápsulas contendo as sementes. A germinação das sementes ocorreu em meio de cultura MS (Murashige \& Skoog, 1962) modificado com a metade da concentração dos macronutrientes acrescido de 


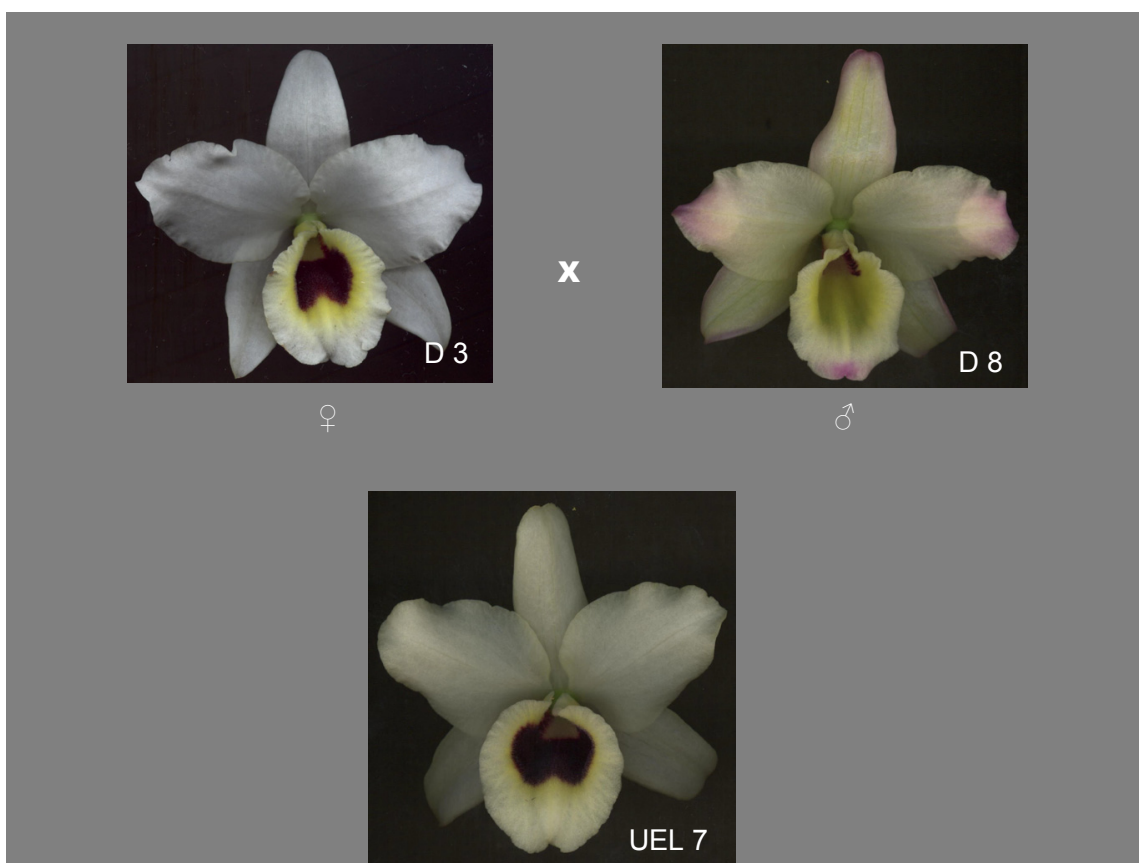

Figura 1. Flores dos genótipos parentais e da cultivar UEL 7 (D3 x D8) (flowers of parental genotypes and of UEL 7 cultivar (D3 x D8). Londrina, UEL, 2009.

$1,0 \mathrm{~g} \mathrm{~L}^{-1}$ de carvão ativado, $30,0 \mathrm{~g} \mathrm{~L}^{-1}$ de sacarose e 7,0 $\mathrm{g} \mathrm{L}^{-1}$ de ágar, e o $\mathrm{pH}$ ajustado para 6,3. As plântulas obtidas foram subcultivadas e com $6 \mathrm{~cm}$ de altura transferidas para bandejas de isopor de $25 \times 25 \mathrm{~cm}$, utilizando esfagno como substrato e colocadas em estufa coberta com plástico e sombrite com $50 \%$ de sombreamento para aclimatização e finalmente replantadas para vasos individuais. Em Londrina, o florescimento ocorre nos meses de agosto e setembro.

\section{CARACTERÍSTICAS}

UEL 7 é uma planta de pseudobulbos com altura média de $44 \mathrm{~cm}$. As flores de coloração amarela, (Figura 1), possuem em média 7,0 cm de diâmetro, e o labelo com $3,0 \mathrm{~cm}$ de largura e 3,1 $\mathrm{cm}$ de comprimento. No florescimento, o pseudobulbo apresenta em média 11 flores. As flores têm durabilidade de aproximadamente 30 dias.

\section{MANUTENÇÃO E DISTRIBUIÇÃO DE PLANTAS}

Plantas da cultivar UEL 7 são mantidas pelo Departamento de Agronomia da Universidade Estadual de Londrina, C. Postal 6001, 86051-990 Londrina-PR, plantadas em vasos plásticos tendo uma mistura de fibra de casca de coco com casca de pínus $(1: 1, \mathrm{v}: \mathrm{v})$ como substrato, em casa de vegetação com cobertura plástica e sombrite de $50 \%$ de sombreamento.

\section{REFERÊNCIAS}

ABCSEM. 2011, 1 de agosto. Floricultura do CE quer exportar US\$ 5,5 milhões. Disponível em: $<$ http://www.abcsem.com.br/noticia. php?cod=1208>

FARIA RT; TAKAHASHI LSA; LONE AB. 2009. UEL 6: nova cultivar de Dendrobium. Horticultura Brasileira 27: 114-115.

JUNQUEIRA AH; PEETZ MS. 2011. Análise conjuntural do comércio do comércio exterior da floricultura brasileira. Disponível em: $<$ http://www.ibraflor.com/publicacoes/ vw.php?cod $=8>$. Acessado em 1 de agosto de 2011.

KAMEMOTO H; AMORE TD; KUEHNLE AR. 1999. Breeding Dendrobium orchids in Hawaii. Honolulu: University of Hawaii Press. 166p.

MURASHIGE T; SKOOG F. 1962. A revised medium of rapid growth and bioassay with tobacco tissue cultures. Physiologia Plantarum 15: 473-479.

SUTTLEWORTH FS; ZIM HS; DILON GW. 1913. Orquídeas: guia dos orquidófilos. Tradução: LEMA FILHO JG. 1994. Rio de Janeiro: Editora Expressão e Cultura. 158p. 